\title{
ESTUDIO CONCEPTUAL DEL TÉRMINO «VIOLENCIA DE GÉNERO» EN LA LEY ESTATAL Y AUTONÓMICA
}

\author{
Melania PALOP BeLloch \\ Doctora en Derecho \\ Universidad Jaume I \\ melaniapalop@botmail.com
}

\section{DIFERENCIA ENTRE EL CONCEPTO DE VIOLENCIA DE GÉNERO Y VIOLENCIA DOMÉSTICA}

Hay dos términos diferenciados respecto a la violencia ejercida contra la mujer: violencia de género y violencia doméstica ${ }^{1}$. El Código Penal en el art. 153 realiza una diferencia conceptual muy clara. Este artículo en su apartado primero se refiere al concepto de violencia de género y en el apartado segundo al concepto de violencia doméstica. Por violencia de género se refiere a los actos violentos repetitivos cometidos por el varón contra su esposa, exesposa o mujer ${ }^{2}$ con la que tenga o haya tenido análoga relación de afectividad aun sin convivencia (pareja de hecho o novia) y haya una voluntad de someter a la mujer a sus deseos.

La idea anterior es apoyada por la mayoría de la doctrina, destacando a Gimeno Reinosa que dice: «La aplicación del art. 153.1 CP exige un plus, un elemento adicional, cual es que esa conducta violenta o de maltrato pueda catalogarse como una manifestación de la discriminación, de la situación de desigualdad y las relaciones de poder de los hombres sobre las mujeres» ${ }^{3}$. También la Exposición de Motivos de la Ley Orgánica de Medidas de Protección Integral contra la Violencia de Género

1 Vid. SAP Castellón, Sección 2. a , resolución núm. 292/2010.

SAP Teruel, Sección 1. ${ }^{a}$, resolución núm. 33/2012, y SAP Castellón, Sección 2. ${ }^{a}$, resolución núm. 213/2015.

2 B. Gimeno Reinosa y V. Barrientos Silva, «Violencia de género versus violencia doméstica: la importancia de la especificidad», Revista venezolana de estudios de la mujer, vol. 14, núm. 32 (2009), p. 36.

3 Ibid., p. 37. 
(en adelante, LOMPIVG) 1/ $04{ }^{4}$ coincide con el Código Penal. Lo considera «una violencia ejercida contra las mujeres por el simple hecho de serlo, provocando discriminación» ${ }^{5}$.

El apartado segundo del mismo artículo califica a la violencia doméstica como la realizada por un varón dentro del domicilio común cometida contra personas vinculadas afectiva o familiarmente al agresor (ascendientes, descendientes, hermanos propios o del cónyuge, o conviviente) o con las que convive (menores o incapaces convivientes o sujetos a patria potestad, tutela, curatela, acogimiento o guarda del cónyuge o conviviente, u otras personas integradas en la familia). Estas personas están enumeradas en el art. 173.2 del Código Penal (en adelante, CP), con excepción de las personas reguladas en art. 153.1, es decir, excluye al cónyuge, pareja de hecho o novia, bien sean actuales o pasados.

También la jurisprudencia coincide con el concepto inicial de violencia doméstica, destacando entre toda la jurisprudencia existente, incluidas instancias superiores, el Auto núm. 282/06, de 12 de julio (ARP 2007/106), donde este concepto lo relaciona con «ámbito doméstico». En primer lugar, se hace referencia al ámbito espacial y afectivo en el que se desarrollan las relaciones de convivencia familiar y, en segundo lugar, lo categoriza a fenómeno sociológico caracterizado por el abuso o dominación por parte de uno de los miembros o sujetos de dichas relaciones familiares sobre otros sujetos de las mismas ${ }^{6}$.

Gimeno y Barrientos ${ }^{7}$ introducen un nuevo elemento a tener en cuenta para diferenciar el concepto de violencia de género y doméstica. En la misma línea que la doctrina, legislación y jurisprudencia coinciden con el concepto dado a la violencia doméstica producido en el ámbito doméstico y privado, mientras que la violencia de género la asimilan a la producida por parte del hombre contra la mujer en cualquier ámbito de la sociedad debido a los estereotipos de género concebidos por la cultura patriarcal. A continuación se expone de forma gráfica la diferencia entre violencia de género y doméstica:

${ }^{4}$ En lo sucesivo la Ley 1/2004, de Medidas de Protección contra la Violencia de Género, la denominaremos LVG.

5 E. Martínez García, Ley de Protección Integral contra la Violencia de Género, Valencia, Tirant lo Blanch, 2005, p. 19.

${ }^{6}$ SAP Castellón, Sección 2. ${ }^{a}$, resolución núm. 213/2015, y STS, Sala de lo Penal, Sección $1 .{ }^{a}$, resolución núm. 559/2010, de 9 de junio. Vid. también I. Montalbán Huertas, «Malos tratos, violencia doméstica y violencia de género desde el punto de vista jurídico», FOM, núm. 12 (2007), p. 8.

7 B. Gimeno Reinosa y V. Barrientos Silva, «Violencia de género versus violencia doméstica...», op. cit., p. 37. 


\begin{tabular}{|l|l|l|}
\hline Diferencias & \multicolumn{1}{|c|}{ Violencia doméstica } & \multicolumn{1}{c|}{ Violencia de género } \\
\hline $\begin{array}{l}\text { Sujeto } \\
\text { activo }\end{array}$ & $\begin{array}{l}\text { Cualquier persona integrante del } \\
\text { núcleo familiar (varón o mujer). }\end{array}$ & $\begin{array}{l}\text { El marido, exmarido, pareja, } \\
\text { expareja, novio, exnovio, aun sin } \\
\text { convivencia. }\end{array}$ \\
\hline $\begin{array}{l}\text { Sujeto } \\
\text { pasivo }\end{array}$ & $\begin{array}{l}\text { Cualquier persona (varón o mujer) } \\
\text { integrante del mismo núcleo familiar } \\
\text { que el agresor (las personas menciona- } \\
\text { das en el art. 173.2 del Código Penal), } \\
\text { excepto la cónyuge, excónyuge, pare- } \\
\text { ja o expareja, o relación análoga de } \\
\text { afectividad. }\end{array}$ & $\begin{array}{l}\text { Mujer, exmujer, pareja, expa- } \\
\text { reja, novia, exnovia o relación } \\
\text { análoga de afectividad aun sin } \\
\text { convivencia. }\end{array}$ \\
\hline Tiempo & $\begin{array}{l}\text { Requiere habitualidad (varias accio- } \\
\text { nes durante un periodo de tiempo que } \\
\text { produzcan violencia). }\end{array}$ & $\begin{array}{l}\text { No requiere habitualidad. Una } \\
\text { sola acción violenta es suficiente. }\end{array}$ \\
\hline Regulación & Arts. 153.2 y 173.2 CP. & Arts. 153.1 y 148.4 CP. \\
\hline
\end{tabular}

\section{ANÁLISIS DEL CONCEPTO DE VIOLENCIA DE GÉNERO EN LA LEY 1/2004, DE 28 DE DICIEMBRE, DE MEDIDAS DE PROTECCIÓN INTEGRAL CONTRA LA VIOLENCIA DE GÉNERO}

La LOMPIVG define el concepto de violencia en sus arts. 1 y 3 . Establece la intervención pública desde una perspectiva integral y multidisciplinar. Evita las relaciones de violencia en el seno de las relaciones afectivas adoptando medidas protectoras, educativas, sociales, asistenciales y de atención posterior a las víctimas. La Ley tiene un carácter transversal dirigido a la sensibilización, prevención y detección temprana.

Según el art. 1: «La presente Ley tiene por objeto actuar contra la violencia que, como manifestación de la discriminación, la situación de desigualdad y las relaciones de poder de los hombres sobre las mujeres, se ejerce sobre éstas por parte de quienes sean o hayan sido sus cónyuges o de quienes estén o hayan estado ligados a ellas por relaciones similares de afectividad, aun sin convivencia», y en el art. 3 enumera los tipos de violencia: «Física y psicológica, incluidas las agresiones a la libertad sexual, las amenazas, las coacciones o la privación arbitraria de libertad» ${ }^{8}$.

Cabe destacar en esta definición que la violencia es ejercida como manifestación del poder y dominación del varón sobre la mujer dentro del ámbi-

\footnotetext{
${ }^{8}$ E. Martínez García, Ley de Protección Integral..., op. cit., p. 27.
} 
to de pareja, ya sea como cónyuges, parejas de hecho, expareja, relación de noviazgo o análoga relación de afectividad aun sin convivencia. Quedaría fuera de este concepto las relaciones esporádicas entre un hombre y una mujer, al no haber una relación de afectividad sólida de futuro.

También se excluye la violencia ejercida contra las personas mencionadas en el art. 173.2 CP realizadas en el ámbito doméstico o en el ámbito familiar, es decir, tal y como dice García Rojas, «quedarían fuera las agresiones que, aun sufriéndolas la mujer y realizadas en el mismo ámbito de relaciones de afectividad por uno de los miembros masculinos de la familia, el vínculo que le une no es el de cónyuge o pareja»?

La LOMPIVG no regula otras formas de violencia contra la mujer realizadas en el ámbito público como: prostitución forzada, infanticidio de niñas, mutilación genital, explotación, acoso, abuso o agresión sexual a mujeres, siempre que no exista un vínculo marital o sentimental entre el sujeto activo y pasivo de la acción. Tampoco caben las relaciones de pareja entre dos personas del mismo sexo, ya que no se consideraría violencia de género al no ser ejercida por un hombre hacia una mujer.

Pero tras la Ley 13/2005, de 1 julio, de modificación del Código Civil en materia de derecho a contraer matrimonio (BOE núm. 157, de 2 de julio de 2005), se asimila la pareja heterosexual a las parejas homosexuales, aunque a pesar de ello en la LOMPIVG no cabría su aplicación al no concurrir la condición de varón en un sentido biológico en la figura del sujeto activo, y lo mismo en el sujeto pasivo la condición biológica de «femenino».

Sin embargo, se aplica en parejas transexuales al cumplirse la figura del sujeto activo en un varón que debería estar operado si biológicamente no es «hombre» y el sujeto pasivo en una mujer al estar intervenida quirúrgicamente de la parte genital inferior y superior (si solamente tiene operados los pechos no se le podría aplicar la condición, aunque mediante informes psicológicos o médico-forenses se podría incluir) ${ }^{10} \mathrm{y}$ sin necesidad de inscribir su cambio de sexo en el Registro Civil.

Cabe poner de manifiesto que la presente Ley entiende como formas de violencia: física, sexual y psicológica, dejando al margen la violencia económica. Este último tipo de violencia se debería incluir al ser el tipo de violencia más peligroso y utilizado en las relaciones de pareja con con-

9 A. D. GaRCía Rojas, Violencia escolar y de género: conceptualización y retos educativos, Huelva, Universidad de Huelva, 2012, p. 60.

${ }^{10}$ La Fiscalía General del Estado en su Circular 6/2011. 
vivencia en un mismo domicilio. Ella normalmente no dispone del dinero ganado con su trabajo o al no trabajar es sometida económicamente a la voluntad de él.

Este estudio considera a los tipos de violencia referentes a amenazas, coacciones y privación arbitraria de la libertad, incluidos en la forma de violencia física, psicológica y violencia sexual. La LOMPIVG cumple catorce años y es necesario adecuarla a los tiempos actuales, por eso desde la Comisión de Igualdad del Senado se ha solicitado a los responsables en el desarrollo de esta Ley su opinión respecto a su modificación ${ }^{11}$. Sin embargo, todavía no hay un consenso. Cabría realizar un concepto de violencia más amplio, incluyendo todas las formas de violencia contra la mujer.

Ley Orgánica 1/2004, de 28 de diciembre, de Medidas de Protección Integral FORMAS DE VIOLENCIA

Física.

Psicológica.

Sexual.

Amenazas.

Coacciones.

Privación arbitraria de la libertad.

\section{ANÁLISIS DEL CONCEPTO DE VIOLENCIA DE GÉNERO EN LAS LEYES AUTONÓMICAS}

A continuación se muestra un análisis conceptual de las diferentes leyes autonómicas sobre violencia hacia las mujeres. Cabe mencionar que las ciudades autónomas de Ceuta y Melilla se rigen por la Ley estatal. La mayoría de las Comunidades Autónomas tiene sus propias normas específicas sobre violencia de género ${ }^{12}$. En este estudio no se van a tomar en consideración los tipos de violencia como la coerción, la privación de libertad y otras manifestaciones expresadas en las leyes porque se entienden englobadas dentro de los cuatro tipos de violencia: física, psicológica, sexual y económica.

${ }^{11}$ Europa Press, Madrid, 4 de noviembre de 2014, disponible en http://www.europapress. es/epsocial/politica-social/noticia-gobierno-centrara-nueva-campana-sensibilizacion-violencia -genero-adolescentes-20141104152549. btml.

${ }_{12}$ Recogidas en Observatorio Jurídico-Laboral de la Violencia de Género, disponible en bttp://www.olvg.uma.es. 
Todas estas leyes orgánicas tratan la violencia de género de una forma integral y multidisciplinar, es decir, abarcando y aplicando programas en distintos ámbitos como: la prevención y sensibilización en el ámbito educativo, en el ámbito de la publicidad y de los medios de comunicación, en el ámbito sanitario, derechos de las mujeres víctimas de violencia de género a la información, a la asistencia jurídica gratuita, asistencia social integral, los derechos laborales, prestaciones de la Seguridad Social y ayudas económicas.

\section{ANDALUCÍA}

La Ley 13/2007, de 26 de noviembre, de Medidas de Prevención y Protección Integral contra la Violencia de Género ${ }^{13}$, en su art. 1 define el concepto de violencia como: «Tiene por objeto actuar contra la violencia que se ejerce sobre las mujeres por el hecho de serlo, como manifestación de la discriminación, la situación de desigualdad y las relaciones de poder de los hombres sobre las mismas».

En su art. 3.2 enumera los tipos de violencia: «Física, sexual, económica o psicológica de la mujer, incluyendo amenazas de dichos actos, coerción o privaciones arbitrarias de su libertad, tanto si se producen en la vida pública como privada». En este estudio se considera que «las amenazas de dichos actos, coerción o privaciones arbitrarias de su libertad» quedarían subsumidas dentro de los otros tipos de violencia física, psicológica, sexual y económica dependiendo de su manifestación y derivación en cualquiera de ellos.

En el art 3.3 define cada uno de los tipos de violencia: a) violencia física: referido a lesiones producidas en el cuerpo de la mujer «ejercida por quien sea o haya sido su cónyuge o por quien esté o haya estado ligado a ella por análoga relación de afectividad, aun sin convivencia»; también lo amplía a cualquier varón de su «entorno familiar o en su entorno social y/o laboral»; $b$ ) violencia psicológica: se refiere a insultos y humillaciones mediante «exigencia de obediencia o sumisión» ejercida por quien sea o haya sido su cónyuge o por quien esté o haya estado ligado a ella por análoga relación de afectividad, aun sin convivencia; asimismo, tendrán la consideración de actos de violencia psicológica contra la mujer los ejerci-

${ }_{13}$ Ley 13/2007, de 26 de noviembre, de Medidas de Prevención y Protección Integral contra la Violencia de Género de Andalucía. 
dos por hombres en su entorno familiar o en su entorno social y/o labo$\mathrm{ral}$; c) violencia económica: supone la privación intencionada de dinero a la mujer para satisfacer sus necesidades y las de sus hijos con independencia de quién aporte dichos recursos monetarios; $d$ ) violencia sexual y abusos sexuales: son agresiones o abusos sexuales no consentidos por parte del varón hacía la mujer mediante coacción e intimidación «con independencia de que el agresor guarde o no relación conyugal, de pareja, afectiva o de parentesco con la víctima».

Andalucía cohesiona el concepto de violencia con los tipos de violencia. De esta manera, la violencia física, psicológica y sexual las vincula con «los ejercidos por los hombres en su entorno familiar o en su entorno social y/o laboral». Se trata de un concepto extenso al ampliar la figura del sujeto activo a cualquier varón. Sin embargo, el tipo de violencia económica restringe su ámbito de comisión a «la convivencia de pareja» ejercida por el marido, pareja o relación análoga de afectividad. Por tanto, el concepto de violencia doméstica está incluido dentro del concepto de violencia de género al referirse a una relación sentimental o marital entre el sujeto activo y pasivo de la acción.

\section{ARAGÓN}

Se aprobó la Ley 4/2007, de 22 de marzo, de Prevención y Protección Integral a las Mujeres Víctimas de Violencia ${ }^{14}$. En su art. 1 se define el concepto de violencia de género: «Todo acto o agresión [...] motivado por la pertenencia a dicho sexo [...] un daño físico o psicológico, situación de debilidad, dependencia o proximidad física, psicológica, familiar, laboral o económica de la víctima frente al agresor».

Los tipos de violencia enumerados en este artículo son: «Las agresiones a su libertad e indemnidad sexuales, incluida la amenaza de tales actos, la coacción o la privación arbitraria de libertad». Éstos los considero incluidos en los tipos de violencia física, psicológica, sexual y económica.

$\mathrm{El}$ art. 2 enumera las conductas: a) «malos tratos físicos; b) malos tratos psicológicos; $c$ ) malos tratos sexuales; $d$ ) agresiones y abusos sexuales a niñas o adolescentes o corrupción de las mismas; $e$ ) acoso sexual; $f$ ) tráfico o utilización de la mujer con fines de explotación sexual, prostitu-

${ }^{14}$ Ley Orgánica 4/2007, de 22 de marzo, de Prevención y Protección Integral a las Mujeres Víctimas de Violencia en Aragón. 
ción y comercio sexual; $g$ ) mutilación genital femenina; $h$ ) violencia contra los derechos sexuales y reproductivos de la mujer; i) maltrato económico; j) cualesquiera otras formas análogas que lesionen o sean susceptibles de lesionar la dignidad de la mujer».

En el art. 3 define al autor de la violencia: «a) por quienes sostienen o han sostenido un vínculo afectivo, conyugal, de pareja, paterno-filial o semejante con la víctima; b) vínculo laboral o docente o de prestación de servicios; $c$ ) violencia social». Así pues, trata a la violencia doméstica como la ejercida por el marido, exmarido, pareja, expareja o análoga relación de afectividad contra la mujer o cualquiera de las personas mencionadas «paterno-filial o semejante con la víctima».

Este tipo conceptual de violencia doméstica incluye a todos los tipos de violencia de género, como la violencia física, psicológica, económica y sexual, a diferencia de la Comunidad Autónoma de Andalucía, que sólo considera al tipo de violencia económica equivalente a la violencia doméstica al ser ejercido contra la mujer exclusivamente.

Aragón define la violencia de género mediante sus ámbitos de aplicación, como el ámbito laboral, docente y social, aplicando un concepto de violencia de género amplio al ser realizado por cualquier varón con una relación contractual o personal con la víctima y mediante la violencia física, psicológica, sexual y económica.

\section{CANARIAS}

En Canarias se aprueba la Ley 16/2003, de 8 de abril, de Prevención y Protección Integral de las Mujeres contra la Violencia de Género ${ }^{15}$. El art. 2 entiende por violencia contra las mujeres: «Con independencia de la edad [...] a través de medios físicos o psicológicos, incluyendo las amenazas, intimidaciones o coacciones [...] daño o sufrimiento físico, sexual o psicológico para la mujer [...] situación de debilidad, de dependencia física, psicológica, familiar, laboral o económica de la víctima frente al agresor».

$\mathrm{El}$ art. 3 dispone las formas de violencia contra las mujeres: «a) físicos; b) psicológicos; c) sexuales [...] relación conyugal, de pareja, afectiva y de parentesco con la víctima; $d$ ) sexuales a menores; $e$ ) acoso sexual [...] superioridad laboral, docente o análoga; f) el tráfico de mujeres con explota-

${ }^{15}$ Ley Orgánica 16/2003, de 8 de abril, de Prevención y Protección Integral de las Mujeres contra la Violencia de Género en Canarias. 
ción sexual, prostitución y comercio sexual, cualquiera que sea el tipo de relación; $g$ ) mutilación genital femenina; $b$ ) derechos sexuales y reproductivos de las mujeres; i) económicos, el ámbito familiar o de pareja; $j$ ) otras formas análogas».

$\mathrm{El}$ art. 4 establece las situaciones de violencia doméstica: «a) por quienes sostienen o han sostenido un vínculo afectivo, conyugal, de pareja, paterno-filial o semejante [...] por relación conyugal o análoga relación de afectividad, sobre los hijos propios o del cónyuge o conviviente, pupilos, ascendientes o incapaces o sujetos a la potestad, tutela, curatela, acogimiento o guarda de hecho; $b$ ) violencia laboral y docente; $c$ ) social».

Se considera la inclusión en la LOMPIVG de las formas de violencia enumeradas en el art. 3. La Ley Canaria iguala el concepto de violencia doméstica al de género, puesto que es realizada por el marido, exmarido, pareja, expareja o análoga relación de afectividad contra la mujer o cualquiera de las personas mencionadas en el art. 173.2 CP. No excluye a la mujer, exmujer o pareja de hecho tal y como hace el art. 153.2 CP. La conceptuación de la violencia doméstica incluye todos los tipos de violencia de género: física, psicológica, económica y sexual.

En cuanto a la violencia de género, la define mediante la enumeración de sus ámbitos de aplicación: laboral, docente y social. Por tanto, se trata de un concepto de violencia de género amplio al ser realizado por cualquier varón mediante una relación contractual o personal en dichos ámbitos, pudiendo producirse en todos ellos la violencia física, psicológica, sexual y económica.

\section{CANTABRIA}

Cantabria se regula por la Ley 1/2004, de 1 de abril, Integral para la Prevención de la Violencia contra las Mujeres y la Protección a sus Víctimas. Después de su entrada en vigor se han dictado diferentes decretos, órdenes y resoluciones de desarrollo, mereciendo especial atención el Decreto 64/2006, de 8 de junio ${ }^{16}$.

El art. 2 de la dicha Ley define el concepto de violencia de género: «Conducta activa u omisiva de violencia o agresión, amenaza, coacción o

${ }^{16}$ Ley $1 / 2004$, de 1 de abril, Integral para la Prevención de la Violencia contra las Mujeres y la Protección a sus Víctimas en Cantabria, y Decreto 64/2006, de 8 de junio, de desarrollo de la Ley. 
privación ilegítima de libertad y la intimidación [...] daño o sufrimiento físico, sexual o psicológico en público o vida familiar o privada». El art. 4 establece el ámbito de aplicación a «todas las mujeres víctimas de actos de violencia de género en el territorio de la Comunidad Autónoma de Cantabria».

$\mathrm{El}$ art. 3 define las formas de violencia: «a) físicos; $b$ ) psicológicos; c) económicos; $d$ ) agresiones sexuales; $e$ ) abusos sexuales a niñas; $f$ acoso sexual; $g$ ) el tráfico de mujeres y niñas de explotación sexual, prostitución y comercio sexual; $b$ ) mutilación genital femenina con el consentimiento, expreso o tácito; $i$ ) derechos sexuales y reproductivos; $j$ ) cualesquiera otras actuaciones o conductas».

Respecto a las formas de violencia enumeradas en el art. 2 de la Ley de Cantabria, incluiríamos todas ellas en los diferentes tipos de violencia enumerados en la LOMPIVG, cuyos tipos de violencia son: física, sexual, psicológica y económica, dependiendo las manifestaciones en que se deriven cada una de ellas.

La Ley cántabra trata la violencia de género de una forma amplia al enumerar en su art. 3 las formas de violencia, dejando el artículo abierto a otras nuevas formas de violencia que puedan aparecer y lesionar los bienes jurídicos de la víctima sin mencionar al sujeto activo de las mismas, pudiendo ser cualquiera, es decir, se presupone que el autor de las formas de violencia es un varón, aunque no deja clara la condición sexual del autor del hecho punible.

En cuanto al sujeto pasivo, claramente se refiere a la mujer. Estas formas de violencia pueden producirse tanto en el ámbito público, privado o familiar. Se entiende por «público» a cualquier tipo de prestación de servicios o relación personal con la víctima en el ámbito social, laboral, docente y comunitario. Así pues, por «privado» se cree cualquier relación personal del sujeto pasivo con el sujeto activo. Y por «familiar» se piensa que el sujeto pasivo y activo de la acción son de la misma unidad familiar.

Por otra parte, la Ley cántabra no delimita la condición del sujeto activo de la acción en la figura del marido, exmarido, pareja, expareja o análoga relación de afectividad con la víctima, sino que sujeto activo puede ser cualquier persona sin esclarecer la condición sexual de ella. Además, algunas formas de violencia enumeradas forman parte del ámbito público y deja un cajón de sastre donde poder incluir otras formas de violencia, por eso se entiende que el concepto de violencia de género y doméstica es un concepto amplio. 


\section{CASTILLA-LA MANCHA}

Se aprobó la Ley 5/2001, de 17 de mayo, de Prevención de Malos Tratos y Protección a las Mujeres Maltratadas ${ }^{17}$. El Consejo de Gobierno de la Comunidad Autónoma aprobó el Decreto 38/2002, de 12 de marzo, que desarrolla las previsiones contenidas en la misma. Fue una ley pionera en España por su anterioridad a la LOMPIVG.

No se delimita la condición del sujeto activo de la acción en la figura del marido, exmarido, pareja, expareja o análoga relación de afectividad con la víctima, sino que puede ser cualquier persona sin esclarecer su condición sexual. Además cabe su aplicación a cualquier mujer en su condición de sujeto pasivo de la acción, con independencia de tener algún tipo de relación personal o de prestación de servicios con el autor del hecho punible de la acción.

Por ello, el concepto de violencia de género y doméstica determinado en dicha Ley es un concepto amplio que podría aplicarse tanto en el ámbito público como privado. Se entiende por «público» cualquier tipo de prestación de servicios o relación personal con la víctima en el ámbito social, laboral, docente y comunitario, y por «privado» cualquier relación personal-afectiva del sujeto pasivo con el sujeto activo.

Es una Ley de ámbito y de aplicación local, es decir, solamente para las ciudadanas cántabras empadronadas en el censo local, aunque amplía su ámbito de aplicación a las mujeres que sufren «trata con fines de explotación sexual, prostitución o comercio sexual» al ser mencionadas expresamente en el art. 4 de su Ley.

\section{CASTILLA Y LEÓN}

Se aprobó la Ley 13/2010, de 9 de diciembre, contra la Violencia de Género en Castilla y León ${ }^{18}$. Su art. 2, apartado 1. ${ }^{\circ}$, establece el concepto de violencia de género: «Cualquier acto de violencia hacia las mujeres que se ejerce contra ellas por el hecho de serlo y que tenga o pueda tener como resultado un daño o sufrimiento físico, sexual o psicológico, incluyendo las

${ }_{17}$ Ley 5/2001, de 17 de mayo, de Prevención de Malos Tratos y Protección a Mujeres Maltratadas en Castilla-La Mancha, y Decreto 38/2002, de 12 de marzo, que desarrolla las previsiones contenidas en la misma.

${ }^{18}$ Ley 13/2010, de 9 de diciembre, contra la Violencia de Género en Castilla y León. 
amenazas de tales actos, la coacción o la privación arbitraria de la libertad, tanto si se produce en la vida pública como privada».

En el apartado segundo del mismo artículo se establecen las formas de violencia de género: «a) física; $b$ ) psicológica; $c$ ) sexual; d) económica; e) tráfico y trata de mujeres y niñas con fines de explotación; $f$ ) aplicación de tradiciones culturales; $g$ ) acoso sexual; $b$ ) acoso laboral; i) cualquier otra forma». Estas formas de violencia las consideramos subsumidas en los diferentes tipos de violencia enumerados en la LOMPIVG, cuyos tipos de violencia son: física, sexual, psicológica y económica, dependiendo de las manifestaciones en que se deriven cada una de ellas.

El párrafo segundo de dicho artículo define los ámbitos de aplicación de las formas de violencia y son: «Ámbito de la pareja, expareja o relación de afectividad análoga, ámbito familiar, ámbito laboral, ámbito social o comunitario». El concepto de violencia de género presentado por esta Ley enumera como sujeto activo a la pareja, expareja o análoga relación de afectividad.

Sin embargo, también aplica un concepto de violencia en sentido amplio, ya que ésta puede ser ejercida por cualquier otro varón en el ámbito laboral, docente, social y comunitario fruto de una relación personal o de prestación de servicios. Estos ámbitos de aplicación hacen referencia a la esfera pública. Sin embargo, la violencia económica la asimila al concepto de violencia doméstica y de género al coincidir los mismos sujetos, ya que vincula esta violencia con la relación de pareja donde existe un vínculo marital o de pareja entre el sujeto pasivo y activo.

Además, establece un concepto de violencia doméstica acorde al CP al determinar como sujeto activo de la acción a cualquier varón perteneciente a la unidad familiar y como sujeto pasivo a las mujeres y personas dependientes que forman el núcleo familiar. El concepto de violencia doméstica se realiza en el ámbito privado y familiar, entendiéndose cualquier relación personal del sujeto pasivo con el sujeto activo.

\section{CATALUÑA}

Cataluña se rige por la Ley 5/2008, de 24 de abril, de los Derechos de las Mujeres para la Erradicación de la Violencia Machista ${ }^{19}$. Esta Ley

${ }_{19}$ Ley 5/2008, de 24 de abril, de los Derechos de las Mujeres para la Erradicación de la Violencia Machista en Cataluña. 
no utiliza el término «violencia de género», sino «violencia machista». El art. 3 define «violencia machista» como la violencia ejercida contra las mujeres producto de la discriminación y la situación de desigualdad en las relaciones de poder de los hombres sobre las mujeres. Los tipos de violencia son: físicos, económicos o psicológicos, sexual en el ámbito público y en el privado.

El apartado 1 del art. 3 define la violencia en el ámbito de la pareja. Ésta consiste en la violencia física, psicológica, sexual o económica ejercida por un hombre contra una mujer «que es o ha sido su cónyuge o por la persona que tiene o ha tenido con ella relaciones similares de afectividad».

El apartado 2 del mismo artículo define la violencia en el ámbito familiar. Ésta es ejercida por los miembros varones de la propia familia contra las mujeres y las menores de edad en el núcleo familiar, aunque excluye a la violencia ejercida en las relaciones de pareja.

En su apartado 3 se define a la violencia en el ámbito laboral. Ésta consiste en la realizada en el centro de trabajo y durante la jornada laboral, o fuera del centro de trabajo y del horario laboral, y consiste en: acoso por razón de sexo y acoso sexual. El primer tipo de acoso se realiza contra las mujeres, creándoles un entorno humillante y vejatorio e intentando frenar su carrera profesional. El segundo tipo de acoso se refiere a un comportamiento sexista y libidinoso.

El apartado 4 define la violencia en el ámbito social o comunitario y se refiere a agresiones sexuales, acoso sexual, tráfico y explotación sexual de mujeres y niñas, mutilación genital, matrimonios forzados, conflictos armados (incluye asesinato, violación, esclavitud sexual, embarazo forzado, el aborto forzado, la esterilización forzada, la infección de enfermedades, tortura o abusos sexuales), derechos sexuales y esterilizaciones forzadas. Su apartado 5, a modo de cajón de sastre, amplía a cualesquiera otras formas análogas de violencia contra las mujeres. Claramente legisla tanto la violencia de género como doméstica.

Respecto a las formas de violencia enumeradas en la Ley de Cataluña, incluiríamos todas ellas en los diferentes tipos de violencia enumerados en la LOMPIVG, cuyos tipos de violencia son: física, sexual, psicológica y económica, dependiendo de las manifestaciones en que se deriven cada una de ellas. La presente Ley deja un cajón de sastre pudiendo incorporar cualquier otro tipo de violencia que vulnere los bienes jurídicos de la persona como: «la dignidad, la integridad o la libertad de las mujeres». Estas formas también quedarían subsumidas en la violencia física, psicológica, sexual y económica dependiendo en el tipo de violencia en que derivasen. 
El concepto de violencia doméstica definido en esta Ley se realiza dentro del núcleo familiar y tiene un concepto amplio, puesto que es realizado por cualquier miembro de la familia, excluyendo de forma expresa al marido, exmarido, pareja, expareja o relación análoga de afectividad, y solamente contra la mujer e hijos menores de edad. Por tanto, la presente Ley dota un concepto de violencia de género amplio cuyo ámbito de aplicación es laboral y social.

En el ámbito laboral se hace referencia a relaciones de prestación de servicios entre el sujeto activo y pasivo, mientras que en el ámbito social no se concreta si la violencia ejercida es consecuencia de relaciones personales o de prestación de servicios entre el sujeto activo y pasivo de la acción, aunque también establece un concepto de violencia de género propiamente, puesto que el sujeto activo de la acción es el marido, exmarido, pareja, expareja o relación análoga de afectividad fruto de una relación marital o sentimental de pareja contra el sujeto pasivo de la acción, que recae en la figura de la mujer o pareja sentimental.

\section{COMUNIDAD DE MADRID}

Se aprueba la Ley 5/2005, de 20 diciembre, de Violencia de Género ${ }^{20}$. El art. 2 de la Ley define el concepto de violencia como: «Toda violencia física o psíquica que coarte su libertad corporal, sexual o psicológica ejercida contra ella o sobre menores o dependientes de ella con la intención de causarle perjuicio, creándole un estado de sumisión y pérdida de capacidad de decisión por ella misma».

En cuanto a las formas de ejercer violencia quedan recogidas en el apartado tercero del articulado: «a) agresiones físicas o psíquicas a la mujer con o sin discapacidad por quien sea o haya sido su cónyuge o por quien esté o haya estado ligado a ella por análoga relación de afectividad aún sin convivencia; además el colectivo de mujeres con discapacidad incluye como sujeto activo de la acción a hombres de su entorno familiar o institucional; $b$ ) agresiones y abusos sexuales contra la mujer; c) mutilación genital; d) la prostitución con intimidación, engaño, abuso de superioridad; e) acoso sexual en el ámbito laboral; $f$ ) las detenciones ilegales, amenazas y coacciones; $g$ ) el tráfico de la inmigración clandestina de mujeres con fines de explotación sexual».

${ }^{20}$ Ley 5/2005, de 20 diciembre, de Violencia de Género en la Comunidad de Madrid. 
Respecto a las formas de violencia enumeradas, se incluirían todas ellas en los diferentes tipos de violencia enumerados en la LOMPIVG, cuyos tipos de violencia son: física, sexual, psicológica y económica dependiendo de las manifestaciones en que se deriven cada una de ellas. La presente Ley deja un cajón de sastre para incorporar cualquier otro tipo de violencia que provoque «angustia o miedo y coarte su libertad». Estas formas de violencia quedarían subsumidas en la violencia física, psicológica, sexual y económica dependiendo en el tipo de violencia en que derivasen.

El concepto de violencia de género acuñado en la presente Ley es un concepto amplio respecto al tipo de violencia sexual realizado en el ámbito laboral, puesto que no concreta el sujeto activo de la acción en «quien sea o haya sido su cónyuge o por quien esté o haya estado ligado a ella por análoga relación de afectividad aun sin convivencia», aunque queda claro que la acción debe recaer en una mujer. También este mismo concepto se aplica a las mujeres con discapacidad cuyo sujeto activo del hecho imponible puede ser cualquier varón de su entorno familiar o institucional.

Pero la presente Ley no específica a la violencia económica como un tipo de violencia expresamente, aunque podría ser objeto de protección al entrar dentro de la expresión «cualquier otra situación de angustia o miedo que coarte su libertad» y al tener el sujeto pasivo y activo de la acción un vínculo matrimonial de convivencia. Lo mismo ocurre con la mujer discapacitada cuya violencia económica puede ser realizada por el marido, pareja, exmarido, expareja o relación análoga de afectividad y cualquier miembro varón de la unidad familiar.

Tampoco la Ley habla sobre violencia doméstica, aunque comparte el mismo tenor literal que el Código Penal al poderse realizar por cualquier varón del entorno familiar de la mujer con discapacidad. Sin embargo, adquiere otro alcance el concepto de violencia doméstica en el ámbito de la pareja por su marido, exmarido, pareja, expareja o relación análoga de afectividad contra su mujer no discapacitada o personas dependientes de ésta, ya que sólo extiende su protección a la mujer e hijos menores de edad.

\section{NAVARRA}

Se creó la Ley Foral 22/2002, de 2 de julio ${ }^{21}$, para la Adopción de Medidas Integrales contra la Biolencia Sexista. Fue modificada por la Ley

${ }^{21}$ Ley Foral 22/2002, de 2 de julio, para la Adopción de Medidas Integrales contra la Violencia Sexista en Navarra, modificada por la Ley Foral 12/2003, de 7 de marzo. 
Foral 12/2003, de 7 de marzo, para la Adopción de Medidas Integrales contra la Violencia Sexista. Pero tras la aprobación de la Ley 1/2004, de 28 de diciembre, de Protección Integral contra la Violencia de Género, se rigieron por ella en algunas cuestiones y crearon el Reglamento de Medidas Integrales contra la Violencia Sexista de Navarra mediante el Decreto Foral 16/2007, de 26 febrero, que desarrolla la Ley Foral 22/2002 de 2 de julio. Por tanto, la Ley navarra tiene un concepto de violencia de género y doméstica equivalente al CP.

\section{COMUNIDAD VALENCIANA 22}

La Ley 7/2012, de 23 de noviembre, Integral de la Comunidad Valenciana sobre la Violencia sobre la Mujer ${ }^{23}$. Su art. 2 establece el concepto de violencia como: «Comportamiento de acción u omisión de un hombre contra una mujer mediante daños físicos, sexuales y/o psicológicos, por el hecho de ser mujer y basado en situaciones de desigualdad y de las relaciones de poder en el ámbito público como privado».

En cuanto a las formas de violencia descritas son: «1) la violencia física: 2) la violencia psicológica: 3) la violencia sexual con independencia de la existencia de relación conyugal, de pareja afectiva, de parentesco o laboral con la víctima; 4) violencia económica en el ámbito de convivencia de la pareja o en los casos de ruptura de la relación; 5) mutilación genital; 6) trata de mujeres y niñas».

Todas las formas de violencia enumeradas en esta Ley se incluyen en los diferentes tipos de violencia enumerados en la LOMPIVG, cuyos tipos de violencia son: física, sexual, psicológica y económica, dependiendo las manifestaciones en que se deriven cada una de estas manifestaciones «así como las amenazas de tales actos, la coacción o la privación arbitraria de libertad».

El concepto de violencia lo enlaza con los tipos de violencia. La violencia física y psicológica realiza una descripción sobre ellas sin mencionar el sujeto activo responsable del acto de esa violencia. Lo que se presupone que pueda ser cualquier varón que tenga una relación personal o de prestación de servicios con el sujeto pasivo por su condición de mujer.

22 En adelante CV.

${ }^{23}$ Ley 7/2012, de 23 de noviembre, Integral de la Comunidad Valenciana sobre la Violencia sobre la Mujer. 
En la violencia sexual realiza una descripción sobre su contenido, pero matiza sobre la figura del sujeto activo «con independencia de que aquel guarde o no relación conyugal, de pareja afectiva, de parentesco o laboral con la víctima». Por tanto, de esta aclaración se desprende: que el concepto otorgado por esta Ley al concepto de violencia de género es un concepto amplio en cuanto a los tipos de violencia física, psicológica y sexual, ya que establece que el sujeto activo de la acción puede ser cualquier varón.

También el tipo de violencia económica lo asimila al concepto de género con un alcance más limitado al situar al sujeto activo «en el ámbito de convivencia de la pareja o en los casos de ruptura de la relación», identificándolo en la figura del marido, exmarido, pareja, expareja o relación análoga a la afectividad.

\section{EXTREMADURA}

En Extremadura se crea la Ley 8/2011, de 23 de marzo, de Igualdad entre Mujeres y Hombres y contra la Violencia de Género ${ }^{24}$. No es una ley propiamente integral de violencia de género, sino una ley de igualdad entre hombres y mujeres. No regula el concepto de violencia de género ni las formas de violencia. Por tanto, se regularán los casos de violencia de género conforme a la legislación nacional, ya que carece de ley autonómica.

\section{GALICIA}

Se crea la Ley 11/2007, de 27 de julio, de Violencia de Género ${ }^{25}$. Su art. 1, párrafo 2. ${ }^{\circ}$, define el concepto de violencia de género: «Es un acto violento o agresión en situación de desigualdad y relaciones de dominación de los hombres sobre las mujeres mediante violencia física, sexual o psicológica, incluidas las amenazas, la coacción o la privación arbitraria de la libertad en el ámbito público y en la vida familiar y/o privada».

$\mathrm{El}$ art. 3 de la Ley establece las formas de violencia: «1) violencia física y psicológica [...] ejercida por quien sea o haya sido su cónyuge o por quien esté o haya estado ligado a ella por análoga relación de afectividad,

${ }^{24}$ Ley 8/2011, de 23 de marzo, de Igualdad entre Mujeres y Hombres y contra la Violencia de Género en Extremadura.

${ }^{25}$ Ley 11/2007, de 27 de julio, de Violencia de Género de Galicia. 
aun sin convivencia; igualmente tendrán la consideración de actos de violencia física contra la mujer los ejercidos por hombres de su entorno familiar o de su entorno social y/o laboral; 3 ) violencia económica cuyos sujetos afectados son la mujer y sus hijos; 4) violencia sexual con independencia de que el agresor guarde o no relación conyugal, de pareja, afectiva o de parentesco con la víctima; 5) acoso sexual, prevaliéndose el sujeto activo de una situación de superioridad laboral, docente o análoga; 6) el tráfico sexual de mujeres y niñas; 7) cualquier otra forma de violencia».

Respecto a las formas de violencia enumeradas en el art. 1, párrafo 2. de la Ley se incluirían todas ellas en los diferentes tipos de violencia enumeradas en la LOMPIVG, cuyos tipos de violencia son: física, sexual, psicológica y económica, dependiendo las manifestaciones en que se deriven de cada uno de estos tipos de violencia «las amenazas de tales actos y la coacción o privación arbitraria de la libertad».

$\mathrm{El}$ art. 3 de la Ley amplía nuevas formas de violencia mediante un cajón de sastre, pudiendo incorporar cualquier otro tipo de violencia que provoque en la persona «cualquier otra forma de violencia recogida en los tratados internacionales que lesione o sea susceptible de lesionar la dignidad, la integridad o la libertad de las mujeres». Estas formas también quedarían subsumidas en la violencia física, psicológica, sexual y económica dependiendo en el tipo de violencia en que derivasen.

La presente Ley realiza un tratamiento unificador del concepto de violencia con los tipos de violencia. Asimila el concepto de violencia de género en cuanto a las formas de violencia física y psicológica, ya que identifica al sujeto activo «por quien sea o haya sido su cónyuge o por quien esté o haya estado ligado a ella por análoga relación de afectividad, aun sin convivencia».

Pero, al mismo tiempo, la presente Ley otorga un concepto de violencia de género en sentido amplio, al vincular los tipos de violencia física, psicológica y sexual con un sujeto activo indeterminado, es decir, cualquier varón «de su entorno familiar o de su entorno social y/o laboral». Estos sujetos tendrán una relación con la víctima de prestación de servicios o relación personal en cada uno de estos ámbitos social, laboral y familiar.

La presente Ley establece una conexión entre la violencia económica y el concepto de violencia doméstica al realizarse dentro del núcleo familiar a través de los siguientes sujetos: marido, exmarido, pareja, expareja o relación análoga de afectividad contra la mujer, sus hijos e hijas, es decir, «el ámbito de la convivencia de pareja». Sin embargo, dicho concepto no es idéntico al CP, puesto que el sujeto activo de la acción puede ser cual- 
quier varón que forme parte de la unidad familiar y contra todas las personas enumeradas en su art. 173.2.

\section{ISLAS BALEARES}

Esta Comunidad Autónoma no ha promulgado una ley específica sobre violencia de género, sino que en el capítulo VI del título III, referente a «Actuación administrativa para promover la igualdad en diferentes áreas de intervención», regula este asunto a través de la Ley 12/2006, de 20 de septiembre $^{26}$, para la Mujer. En este capítulo establece una serie de medidas de protección y atención en el marco de la LOMPIVG. No da un concepto de violencia de género ni regula las formas de violencia.

\section{LA RIOJA}

Se crea la Ley 3/2011, de 1 de marzo, de Prevención, Protección y Coordinación Institucional en Materia de Violencia en La Rioja ${ }^{27}$.

$\mathrm{El}$ art. 4 establece el concepto de violencia como todo ataque intencional contra una mujer por su condición sexual que produzca desigualdad y dependencia mediante los tipos de violencia física, psicológica, sexual y económica, siendo ejercida por «parte de quienes sean o hayan sido sus cónyuges o de quienes estén o hayan estado ligados a ella por relaciones de análoga afectividad, aun sin convivencia».

También define la violencia intrafamiliar como la producida por un miembro de la familia contra otro u otros miembros (ascendientes, descendientes o hermanos y menores residentes en el domicilio común) basadas en relaciones de superioridad y dependencia mediante la aplicación de los tipos de violencia física, psicológica y sexual en la vida pública o privada.

En cuanto a la violencia en el ámbito escolar es la realizada en un centro docente o fuera por escolares del centro mediante los tipos de violencia física, psicológica y sexual. Esto supone una novedad respecto a otras Leyes.

\footnotetext{
${ }^{26}$ Ley 12/2006, de 20 de septiembre, para la Mujer en Islas Baleares.

${ }^{27}$ Ley $3 / 2011$, de 1 de marzo, de Prevención, Protección y Coordinación Institucional en Materia de Violencia en La Rioja.
} 
El art. 5 regula las formas de violencia: «a) malos tratos físicos; $b$ ) malos tratos psicológicos; c) malos tratos económicos; $d$ ) malos tratos sexuales; e) agresiones y abusos sexuales a menores; $f$ ) acoso sexual; $g$ ) tráfico sexual con independencia de la edad; b) mutilación genital; i) contra los derechos sexuales y reproductivos de la mujer; $j$ ) acoso escolar y extorsiones; $k$ ) cualesquiera otras formas análogas, incluyendo medios telemáticos, redes sociales e Internet».

Respecto a las formas de violencia enumeradas en el art. 4 de la Ley se incluirían todas ellas en los diferentes tipos de violencia enumeradas en la LOMPIVG, cuyos tipos de violencia son: física, sexual, psicológica y económica, dependiendo las manifestaciones en que se deriven cada uno de estos tipos de violencia «la amenaza de tales actos y conductas, la coacción y la limitación o privación arbitraria de libertad».

El art. 5 de la Ley amplía nuevas formas de violencia mediante un cajón de sastre: «cualesquiera otras formas análogas». También estas formas quedarían subsumidas en la violencia física, psicológica, sexual y económica dependiendo del tipo de violencia en que derivasen. Es novedosa la mención expresa de esta Ley a la utilización de violencia a través del uso de la Tic's.

En esta Ley se da un concepto de violencia de género en sentido amplio y conforme al CP. Éste se identifica con el ámbito de aplicación escolar de la violencia física, psicológica y sexual. No delimita el sujeto activo de la acción, pudiendo realizarla cualquier hombre que tenga una relación de prestación de servicios o personal con el sujeto pasivo. Además, destaca el delito de hostigamiento como forma de ejercer violencia en el ámbito escolar.

En el ámbito intrafamiliar la violencia puede ser ejercida por cualquier varón perteneciente al núcleo familiar de la mujer víctima. Se identifica el ámbito de aplicación «intrafamiliar» dentro del concepto de violencia de género en sentido amplio y no doméstica, porque según la Ley podrá ser realizado tanto en el ámbito público como privado. Se considera ámbito público el derivado del fruto de relaciones personales o de prestación de servicios entre el sujeto activo y pasivo de la acción.

También establece un concepto de violencia de género restringido que recae sobre la mujer producido por el sujeto activo: «por parte de quienes sean o hayan sido sus cónyuges o de quienes estén o hayan estado ligados a ella por relaciones de análoga afectividad, aun sin convivencia».

Relaciona el concepto de violencia doméstica con el tipo de violencia económica al ser realizada dentro del ámbito privado fruto de relaciones 
personales entre el sujeto activo y pasivo. Según la Ley, este tipo de violencia se produce por un sujeto activo determinado en la figura de «por quien sea o haya sido su cónyuge o por quien esté o haya estado ligado a ella por análoga relación de afectividad», es decir, en el ámbito de la pareja y contra la mujer, o sobre descendientes, ascendientes, hermanos por naturaleza y menores. Esta definición de violencia doméstica no guarda relación con el CP, puesto que recae sobre la mujer.

\section{ASTURIAS}

La Ley del Principado de Asturias 2/2011, de 11 de marzo, para la Igualdad de Mujeres y Hombres y la Erradicación de la Violencia de Géne$\mathrm{ro}^{28}$, hace una remisión a la LOMPIVG y al resto de medidas integrales.

\section{MURCIA}

Se crea la Ley 3/2008, de 3 de julio, de modificación de la Ley 7/2007, de 4 de abril, para la Igualdad entre Mujeres y Hombres, y de Protección contra la Violencia de Género en la Región de Murcia ${ }^{29}$.

En la Ley 7/2007, de 4 de abril, se define en el art. 40 el concepto de violencia como todo acto violento físico, psicológico o sexual contra la mujer y sus hijos menores de edad y dependientes por pertenecer al sexo femenino.

El art. 40, párrafo 2. ${ }^{\circ}$, establece las formas de violencia: «a) físicas o psíquicas por quien sea o haya sido su cónyuge o por quien esté o haya estado ligado a ella por análoga relación de afectividad, aun sin convivencia mediante posición de poder; en el caso de mujeres con discapacidad, además de lo anterior, las ejercidas por hombres de su entorno familiar, aunque no tengan la condición de cónyuge o persona con la que esté ligada por análoga relación de afectividad aun sin convivencia; $b$ ) las agresiones y abusos sexuales; $c$ ) la mutilación; $d$ ) la prostitución; $e$ ) el acoso sexual en el ámbito laboral; $f$ ) inmigración clandestina de mujeres».

${ }^{28}$ Ley del Principado de Asturias 2/2011, de 11 de marzo, para la Igualdad de Mujeres y Hombres y la Erradicación de la Violencia de Género.

${ }^{29}$ Ley 3/2008, de 3 de julio, de modificación de la Ley 7/2007, de 4 de abril, para la Igualdad entre Mujeres y Hombres, y de Protección contra la Violencia de Género en la Región de Murcia. 
Respecto a las formas de violencia enumeradas en la Ley de Murcia, se incluirán todas ellas en los diferentes tipos de violencia enumeradas en la LOMPIVG, cuyos tipos de violencia son: física, sexual, psicológica y económica, dependiendo las manifestaciones en que se deriven cada una de ellas.

El concepto de violencia de género acuñado en la presente Ley es un concepto amplio respecto al tipo de violencia sexual, puesto que no concreta al sujeto activo de la acción, pudiendo ser cualquier varón. Lo mismo ocurre respecto a la violencia física y psicológica. No identifica el sujeto activo de la acción en un varón determinado, pudiendo ser cualquier hombre.

Sin embargo, establece un concepto de violencia de género conforme al CP con el tipo de violencia psicológica y física en el art. 40, párrafo 2. ${ }^{\circ}$, al ser ejercida «por quien sea o haya sido su cónyuge o por quien esté o haya estado ligado a ella por análoga relación de afectividad, aun sin convivencia». Lo identifica con la relación marital o de pareja entre el sujeto activo y pasivo de la acción.

En cuanto al concepto de violencia doméstica, lo vincula con el tipo de violencia física y psicológica, y diferencia a la mujer con discapacidad y sin discapacidad. En cuanto a la mujer con discapacidad, establece que el sujeto activo del hecho imponible puede ser cualquier varón de su entorno familiar incluido el cónyuge, excónyuge, pareja, expareja o análoga relación de afectividad.

Sin embargo, la misma Ley establece un concepto de violencia doméstica distinto al dicho anteriormente tanto respecto a la mujer sin discapacidad y con discapacidad. El sujeto activo puede ser el «cónyuge o persona con la que esté ligada por análoga relación de afectividad» contra ella y sus hijos menores o dependientes por razón de su sexo.

Ambos conceptos de violencia doméstica tienen un sentido amplio, ya que no guardan relación con el concepto delimitado en el CP. El CP incluye como sujetos pasivos a las personas enumeradas en el art. 173.2 del mismo cuerpo legal sin hacer distinción «por razón de sexo».

La presente Ley no menciona a la violencia económica como tipo de violencia expresamente, sino que la vincula a través de la relación matrimonial y/o de convivencia entre el sujeto activo y pasivo con discapacidad y sin discapacidad. En el caso exclusivo de la mujer con discapacidad ésta puede ser realizada por cualquier miembro varón perteneciente a la unidad familiar. 


\section{PAÍS VASCO}

Se crea la Ley 3/2012, de 16 de febrero, por la que se modifica la Ley 4/2005, de 18 de febrero, para la Igualdad de Mujeres y Hombres. El concepto de violencia de género está contenido en su capítulo VI del título III de la Ley ${ }^{30}$.

$\mathrm{Su}$ art. 1 establece el objeto de aplicación en el ámbito público y privado. El art. 50 define el concepto de violencia referente a todo acto violento por razón de sexo contra una mujer mediante la violencia física, psicológica y sexual en la vida pública y privada.

En cuanto a estas formas de violencia y «las amenazas de realizar tales actos, la coacción o la privación arbitraria de la libertad» se incluirían todas ellas en los diferentes tipos de violencia enumeradas en la LOMPIVG, cuyos tipos de violencia son: física, sexual, psicológica y económica, dependiendo de las manifestaciones en que se deriven cada una de estas formas de realizar violencia.

El concepto de violencia de género de esta Ley tiene un sentido amplio, puesto que no delimita la figura del sujeto activo en el cónyuge, excónyuge, pareja o expareja, aunque el sujeto pasivo debe ser una mujer.

No menciona a la violencia económica, aunque se presupone su existencia al mencionar expresamente en la Ley «el ámbito privado» como lugar donde se desarrollan las acciones que generan estas formas de violencia como fruto de las relaciones personales entre el sujeto activo y el sujeto pasivo de la acción.

\begin{tabular}{|l|c|c|c|}
\hline \multicolumn{1}{|c|}{ CC. AA. } & $\begin{array}{c}\text { Concepto violencia } \\
\text { género amplio }\end{array}$ & $\begin{array}{c}\text { Concepto violencia } \\
\text { de género }\end{array}$ & $\begin{array}{c}\text { Concepto violencia } \\
\text { doméstica }\end{array}$ \\
\hline Andalucía & $\mathrm{X}$ & $\mathrm{X}$ & \\
\hline Aragón & $\mathrm{X}$ & & $\mathrm{X}$ \\
\hline Canarias & $\mathrm{X}$ & $\mathrm{X}$ & $\mathrm{X}$ \\
\hline Cantabria & $\mathrm{X}$ & & $\mathrm{X}$ \\
\hline Castilla La Mancha & $\mathrm{X}$ & & $\mathrm{X}$ \\
\hline Castilla Y León & $\mathrm{X}$ & $\mathrm{X}$ & $\mathrm{X}$ \\
\hline Cataluña & $\mathrm{X}$ & $\mathrm{X}$ & $\mathrm{X}$ \\
\hline Ceuta & & $\mathrm{X}$ & $\mathrm{X}$ \\
\hline
\end{tabular}

${ }^{30}$ Ley 3/2012, de 16 de febrero, por la que se modifica la Ley 4/2005, de 18 de febrero, para la Igualdad de Mujeres y Hombres en el País Vasco. 


\begin{tabular}{|l|c|c|c|}
\hline \multicolumn{1}{|c|}{ CC. AA. } & $\begin{array}{c}\text { Concepto violencia } \\
\text { género amplio }\end{array}$ & $\begin{array}{c}\text { Concepto violencia } \\
\text { de género }\end{array}$ & $\begin{array}{c}\text { Concepto violencia } \\
\text { doméstica }\end{array}$ \\
\hline Madrid & $\mathrm{X}$ & $\mathrm{X}$ & $\mathrm{X}$ \\
\hline Navarra & & $\mathrm{X}$ & $\mathrm{X}$ \\
\hline Valencia & $\mathrm{X}$ & $\mathrm{X}$ & $\mathrm{X}$ \\
\hline Extremadura & $\mathrm{X}$ & $\mathrm{X}$ & \\
\hline Galicia & & $\mathrm{X}$ & $\mathrm{X}$ \\
\hline Islas Baleares & $\mathrm{X}$ & $\mathrm{X}$ & \\
\hline La Rioja & & $\mathrm{X}$ & $\mathrm{X}$ \\
\hline Melilla & & $\mathrm{X}$ & $\mathrm{X}$ \\
\hline Asturias & $\mathrm{X}$ & $\mathrm{X}$ & $\mathrm{X}$ \\
\hline Murcia & $\mathrm{X}$ & & $\mathrm{X}$ \\
\hline País Vasco & & & \\
\hline & & & \\
\hline
\end{tabular}

\section{RESULTADOS}

1. Todas estas leyes autonómicas, junto con LOMPIVG, establecen medidas de prevención, sensibilización, detección, medidas jurisdiccionales y de derechos de las mujeres víctimas de violencia de género.

2. Conforme al art. 149, párrafo 1. ${ }^{\circ}$, de la Constitución Española ${ }^{31}$, sobre el reparto de competencias entre el Estado y las Comunidades Autónomas, no presenta problemas de competencias, ya que las Comunidades Autónomas junto con el Estado son garantes del cumplimiento de los principios de igualdad y no discriminación de los ciudadanos regulados en el art. 9, párrafo 2. ${ }^{\circ}$, de la Constitución Española, y fruto de ello son estas leyes autonómicas.

3. Dado el carácter multidisciplinar de todas estas leyes autonómicas, el art. 148 , párrafo $1 .^{\circ}$, apartado 20 , les atribuye la competencia en materia de asistencia social para complementar las establecidas por las leyes estatales ${ }^{32}$.

4. Algunas leyes autonómicas tienen un concepto de violencia de género en sentido amplio, ya que no vinculan al sujeto activo de la acción con su cónyuge, excónyuge, pareja, expareja o relación análoga de afectividad aun sin convivencia, sino con cualquier varón que realice la acción de violencia sobre la mujer.

31 En lo sucesivo CE.

32 A. D. García Rojas, Violencia escolar y de género, op. cit., p. 63. 
5. Otras leyes autonómicas tiene el mismo concepto de violencia de género que el $\mathrm{CP}$, identificando al sujeto pasivo con el marido, expareja o relación análoga de afectividad, y al sujeto pasivo con la mujer o exmujer.

6. La violencia de género se produce en el ámbito privado de la pareja, mientras que las leyes autonómicas sobre violencia de género estudiadas se producen tanto en el ámbito privado como público fruto de relaciones personales y de prestación de servicios entre el sujeto activo y el sujeto pasivo en distintos ámbitos sociales, comunitarios, institucionales, laborales, docentes y privados.

7. El concepto de violencia doméstica de las leyes autonómicas reviste diversidad en la figura del sujeto pasivo, pudiendo ser la mujer, exmujer o cualquier mujer o miembro de la unidad familiar. Además, esta violencia se puede producir tanto en el ámbito público como privado. En otras ocasiones coincide con el concepto de violencia doméstica del $\mathrm{CP}$, cuyo sujeto activo es cualquier varón de la unidad familiar, siendo el sujeto pasivo las personas mencionadas en el art. 173.2 CP, exceptuando a la mujer, exmujer o relación análoga de afectividad.

De todas las Comunidades Autónomas cabe destacar que:

1. Trece de estas leyes autonómicas tienen un concepto de violencia de género amplio y estas Comunidades Autónomas son: Andalucía, Aragón, Canarias, Cantabria, Castilla-La Mancha, Castilla y León, Cataluña, Madrid, Galicia, La Rioja, Valencia, Murcia y el País Vasco.

2. Trece de estas leyes autonómicas tienen un concepto de violencia de género propiamente conforme al $\mathrm{CP}$ y estas Comunidades Autónomas son: Andalucía, Canarias, Castilla y León, Cataluña, Madrid, Navarra, Valencia, Extremadura, Galicia, Islas Baleares, La Rioja, Asturias y Murcia.

3. Doce de estas leyes autonómicas tienen un concepto de violencia doméstica conforme al CP y estas Comunidades Autónomas son: Aragón, Canarias, Cantabria, Castilla-La Mancha, Castilla y León, Madrid, Navarra, Extremadura, Islas Baleares, Asturias, Murcia y País Vasco. 


\section{BIBLIOGRAFÍA}

García Rojas, A. D, Violencia escolar y de género: conceptualización y retos educativos, Huelva, Universidad de Huelva, 2012.

Gimeno Reinosa, B., y Barrientos Silva, V., «Violencia de género versus violencia doméstica: la importancia de la especificidad», Revista venezolana de estudios de la mujer, vol. 14, núm. 32 (2009).

Martínez García, E., Ley de protección integral contra la violencia de género, Valencia, Tirant lo Blanch, 2005.

Montalbán Huertas, I., «Malos tratos, violencia doméstica y violencia de género desde el punto de vista jurídico», FOM, núm. 12 (2007).

Muñoz Company, M. ${ }^{a}$ J., «Violencia de género y necesidad o no de elemento subjetivo específico de dominación. Jurisprudencia y legislación reciente», disponible en https://porticolegal.expansion.com/pa_articulo.php?ref=502.

\section{LEGISLACIÓN}

Ley 5/2001, de 17 de mayo, de Prevención de Malos Tratos y Protección a Mujeres Maltratadas en Castilla-La Mancha, y Decreto 38/2002, de 12 de marzo, que desarrolla las previsiones contenidas en la misma.

Ley Foral 22/2002, de 2 de julio, para la adopción de medidas integrales contra la violencia sexista en Navarra, modificada por la Ley Foral 12/2003, de 7 de marzo.

Ley Orgánica 16/2003, de 8 de abril, de Prevención y Protección Integral de las Mujeres contra la Violencia de Género en Canarias.

Ley 1/2004, de 1 de abril, Integral para la Prevención de la Violencia contra las Mujeres y la Protección a sus Víctimas en Cantabria, y Decreto 64/2006, de 8 de junio, de desarrollo de la ley.

Ley Orgánica 1/2004, de 28 de diciembre, de Protección Integral contra la Violencia de Género.

Ley 5/2005, de 20 diciembre, de Violencia de Género en la Comunidad de Madrid.

Ley 12/2006, de 20 de septiembre, para la Mujer en Islas Baleares.

Ley Orgánica 4/2007, de 22 de marzo, de Prevención y Protección Integral a las Mujeres Víctimas de Violencia en Aragón.

Ley 11/2007, de 27 de julio, de Violencia de Género de Galicia.

Ley 7/2012 de 23 de noviembre, Integral de la Comunidad Valenciana sobre la Violencia sobre la Mujer.

Ley 13/2007, de 26 de noviembre, de Medidas de Prevención y Protección Integral contra la Violencia de Género de Andalucía. 
Ley 5/2008, de 24 de abril, de los Derechos de las Mujeres para la Erradicación de la Violencia Machista en Cataluña.

Ley 3/2008, de 3 de Julio, de modificación de la Ley 7/2007 de 4 de abril, para la Igualdad entre Mujeres y Hombres, y de Protección contra la Violencia de Género en la Región de Murcia.

Ley 13/2010, de 9 de diciembre, contra la Violencia de Género en Castilla y León. Ley 3/2011, de 1 de marzo, de Prevención, Protección y Coordinación Institucional en Materia de Violencia en La Rioja.

Ley del Principado de Asturias 2/2011, de 11 de marzo, para la Igualdad de Mujeres y Hombres, y la Erradicación de la Violencia de Género.

Ley 8/2011, de 23 de marzo, de Igualdad entre Mujeres y Hombres, y contra la Violencia de Género en Extremadura.

Ley 3/2012, de 16 de febrero, por la que se modifica la Ley 4/2005, de 18 de febrero, para la Igualdad de Mujeres y Hombres en el País Vasco. 